\title{
Measuring the Effect of Equality Matching Relationships on Lecturers' Knowledge Sharing Behavior
}

\author{
Fibria Indriati* \\ School of Business and Management, Bandung Institute of Technology,, Indonesia \\ Department of Administrative Science, Universitas Indonesia, Indonesia \\ *Corresponding Author Email: fibria.indriati@gmail.com

\section{Prof. Dr. Jann Hidajat Tjakraatmaja} \\ School of Business and Management, Bandung Institute of Technology, Indonesia

\section{Dr. Bambang Rudito} \\ School of Business and Management, Bandung Institute of Technology, Indonesia

\section{Dr. Nurianna Thoha}

Binus Business School, Bina Nusantara University, Indonesia

\section{Doi:10.5901/mjss.2015.v6n6p546}

\section{Abstract}

In a knowledge-based economy - especially in higher education institutions such as universities - human resources have become a valuable asset because of their knowledge. The constant changes and challenges of the application of theories in industry force universities to change and adapt quickly. In university, the creation and application of new knowledge can be achieved by enhancing knowledge-sharing behavior among lecturers. Knowledge-sharing is often erroneously seen as natural activity of lecturers, given their role. In fact, knowledge-sharing is not easily implemented. Lecturers can share and hoard their knowledge as they see fit. There are many factors that can affect knowledge-sharing behavior. One of them is social relationships. This study examines the effect of social relationships on knowledge-sharing behavior among lecturers by using a Theory of Reasoned Action model behavior prediction and equality matching relationship. This study applied a quantitative approach whereby the data were collected using a self-administered questionnaire distributed to 154 lecturers in business and management study programs in Indonesia. The study reveals that equality matching relationships significantly influence a lecturer's attitude toward knowledge-sharing. This type of relationship requires lecturers to have equal and unique knowledge before engaging in knowledge-sharing.

Keywords: Equality Matching Relationship; Knowledge sharing; Subjective Norms; Theory of Reasoned Action

\section{Introduction}

In a knowledge-based economy, knowledge management (KM) has become an important issue in many organizations. Organizations must be able to manage and use knowledge optimally. Organizations do not only have to be able to manage and use it but also have to know how to create, capture, acquire, and distribute it. Knowledge is essential to face rapid changes and challenges in the competitive world.

Implementing knowledge management in an organization can help an organization acquire, manage and distribute knowledge (Davenport \& Prusak, 1998). KM offers a systematic approach to the quality and productivity of knowledge (Drucker, 1994). The knowledge management process consists of capturing, acquiring, sharing, distributing, organizing and using knowledge (Davenport \& Prusak, 1998; Skyrme, 1999). Among those processes, knowledge-sharing is a foundation of KM (Riege, 2005).

The knowledge-sharing process is not only important for for-profit organizations but also for non-profit organizations, especially higher education institutions such as universities. The rapid changes and challenges in theory and practice in industry force universities to change and adapt quickly by creating and applying their knowledge. The demands for creating and developing new knowledge by the university are higher than that for other sectors. This 
challenge is also faced by business and management study programs in universities in Indonesia. Indonesia has more than 2,000 such business and management study programs. Compared to other study programs in Indonesia, business and management study programs make up the majority. Consequently, there is a tight competition among business and management study programs in Indonesia to raise the university ranking, obtain the targeted quantity of students, and maintain the quality of graduates (Lubis, Zamzami, Fatani, Ibrahim \& Dahlan, 2011).To be able to survive and compete, business and management study programs must increase their quality academically and organizationally. One way to do so is by enhancing the knowledge-sharing behavior of its human resources, or more specifically, its lecturers.

Knowledge-sharing can be used to achieve an organization's goals and facilitate the lecturers to elevate their competencies to fulfill their tasks. In Indonesia, every lecturer possesses three main duties known as tri dharma that include teaching, researching, and conducting community service. Those duties should be accomplished equally. It is arguable that knowledge-sharing also helps lecturers prepare the next generation of lecturers.

In an academic world, knowledge-sharing is seen as a desirable and natural activity by lecturers. But in practice, knowledge-sharing is an unnatural process that is not easily implemented (Chong \& Besharati, 2014). It occurs because knowledge is highly personal (Polanyi, 1962) and knowledge-sharing is not only as simple as re-allocation of knowledge. In a knowledge-based economy, people are aware that 'university knowledge' is valuable and important. People are unwilling to share unless there is a benefit for them (Riege, 2005), and therefore they choose with whom, when, and where to share, if at all.

In other words, the success of the knowledge-sharing process depends on the relationships among the people (Lin, Wu, \& Lu, 2012). Different relationships cause different effects on knowledge-sharing behavior. Regarding the type of relationships, Fiske (1992) classified the relationships into four fundamental types of relationships. Those are communal sharing (CR), authority ranking (AR), equality matching (EM), and market pricing (MP) relationships. According to Fiske (1992), people can change their behavior depending on the relationships. Therefore, it is important to examine how the types of relationships affect lecturers' knowledge-sharing behavior in Indonesia.

Since knowledge-sharing is a process that involves exchanging knowledge among individuals and groups (Davenport \& Prusak, 1998), it is assumed that in knowledge-sharing activity there will be a social exchange among individuals. People expect reciprocity in a relationship while they are sharing knowledge. Boer and Berends (2003) found that this kind of relationship is known as an equality matching relationship. In equality matching relationships, the members are egalitarian (Nelson \& Cooprider, 1996). People are only willing to share and contribute if they are sure they will get something in return. The return, in this case, is not only money but also knowledge. People will expect to get knowledge while they are sharing because in knowledge-based organizations like in business and management study programs, knowledge is a valuable asset.

The equality matching relationships do not directly affect lecturers' knowledge-sharing behavior. Equality matching relationships affect one's attitude toward knowledge-sharing behavior and subjective norms concerning knowledgesharing behavior. Many studies have found that attitude and subjective norms toward knowledge-sharing behavior affect intention directly (Bock \& Kim, 2002; Bock, Zmud \& Kim, 2005; Jewels \& Ford, 2006; Jeon, Kim \& Koh, 2011; Chennamaneni, Teng \& Raja, 2012).

Based on the discussions above, this study poses two research questions. First, what is lecturers' perception of knowledge-sharing behavior? Second, how do equality matching relationships affect lecturers' knowledge-sharing behavior? To answer these research questions, this study implemented a quantitative approach and applied a TRA model of behavior prediction and equality matching relationships. The contribution of this study is a validating model to explain the effect of equality matching relationships on knowledge-sharing behavior because such a model has never been verified in previous literature.

This paper is organized into six sections. Section 1 explains the background of the study. Section 2 describes the theoretical framework that supports the study. Section 3 presents the research model, hypotheses and research methodology. Section 4 examines the results. Section 5 discusses the results and limitations of the study.

\section{Theoretical Framework}

\subsection{Knowledge-sharing Behavior}

This section describes the theoretical framework of knowledge-sharing, behavior and lecturer knowledge-sharing behavior. 


\subsubsection{Knowledge-sharing (KS)}

In implementing knowledge management, knowledge-sharing is fundamental because knowledge-sharing is the beginning process, a critical step as an enabler of knowledge management (Alavi \& Leidner, 2001; Lee, 2003). There is no such rigid definition regarding knowledge-sharing. Many experts have defined knowledge-sharing from different points of view. Some of them defined knowledge-sharing as an inter-exchange process between individuals, inter-team and from organization to organization (Davenport \& Prusak, 1998; Sharratt \& Usoro, 2003; Connely \& Kelloway, 2005; Shapira, Youtie \& Jaafar, 2005, Alajmi, 2008; Wang \& Noe, 2010), while others defined knowledge-sharing as knowledge flow (Gupta \& Govindarajan, 2000; Alavi \& Leidner, 2001)

According to Chong \& Besharati (2014, p.178), knowledge-sharing is "personal interaction, mentoring and willingness to share knowledge freely" which means that people are free to choose whether to do it or not. Davenport \& Prusak (1998) stated that knowledge-sharing is a process that involves exchanging knowledge between individual and groups. Even though it is a volunteer activity, it requires an exchange in doing so. Connelly \& Kelloway (2005, p. 294) defined knowledge-sharing as "a set of behaviors that involves an exchange of information or assistance to others." The exchange generally requires reciprocity between individuals.

Knowledge-sharing is the process of disseminating knowledge throughout the organization (Alavi \& Leidner, 2011). This process requires two parties, the knowledge owner, and the receiver. So, the knowledge flows from one to the other(s). The dissemination of knowledge can use several tools such as multimedia, communication tools, the Internet, et cetera. Gupta \& Govindarajan (2000) defined knowledge-sharing as knowledge flow where knowledge-sharing only happens if the source of knowledge has a value to share, a willingness to share the knowledge and the availability of a communication channel. Besides that, it requires the willingness and ability to comprehend of the recipients. As emphasized by Alavi \& Leidner (2001) and Gupta \& Govindarajan (2000), knowledge-sharing depends on not only the source but also the receiver of the knowledge.

From the above definitions, it can be seen that knowledge-sharing involves human interaction. It is a process and can be direct or non-direct. Direct interaction occurs when two people or more meet at the same time, for example faceto-face communication, or a meeting, among others. Indirect interaction means that two people or more interact at a different time and place through media communication such as via email, video conference or Skype.

Based on the above explanations, this study defines knowledge-sharing as an interaction that involves two or more people in exchanging knowledge. In this study, knowledge-sharing is limited to the interaction among lecturers in business and management study programs.

\subsubsection{Behavior}

Much research has been conducted to examine antecedents of knowledge-sharing behavior. But the meaning of behavior itself has almost never been mentioned. Behavior is "internal processes of thinking, feeling, perceiving and judging that lead people to act in particular ways" (Nelson \& Quick, 2012, p.5). Behavior is what people do and say (Miltenberger, 2012) as a response to stimuli.

There are six characteristics of behavior (Miltenberger, 2012). Firstly, human behavior is dynamic; it can be changed. People will do and say different things at different times and places. People will even do and say things differently at the same time and place but to different people. Second, behavior can also be measured with a valid measurement. The occurrences of behavior can be measured by its frequency, duration, and latency. Third, as an action, the behavior is seen and detected by others. Because of this, a behavior can be observed, described, and recorded. Fourth, behavior can affect an environment. It can impact the physical or social environment when/where it occurs. Fifth, behavior is influenced by environment. Lewin (Nelson \& Quick, 2012) defined behavior as the function of personal attitudes and environment. If the environment can affect behavior, therefore people can change the environment to change behavior. Even though it can be seen and is observable, sometimes behavior is hidden. The last characteristics are open (overt) and hidden (covert).

This study defines behavior based on the fifth characteristic; that is, behavior is one's actions which are influenced by one's attitude and environment. The behavior occurs because there are stimuli from within (one's own thinking and experience) and without (the environment). 


\subsubsection{Lecturer Knowledge-sharing Behavior}

Davenport \& Prusak (1998) defined knowledge-sharing behavior as an action conducted by an individual in sharing the knowledge. Ryu, Ho \& Han (2003) used 'degree' terminology to explain knowledge-sharing behavior. Knowledge-sharing behavior is "the degree to which one will share his/her knowledge with others" (Ryu, Ho \& Han, 2003, p.114). This study defines knowledge-sharing behavior as a set of actions that involves exchanging knowledge with others that are influenced by personal attitudes and environments.

In term of lecturers, knowledge-sharing behavior refers to lecturers' actions. Lecturer's knowledge-sharing behavior is a set of lecturers' actions that involves exchanging knowledge with others within an organization. The occurrence of this behavior depends on the stimuli; specifically, this study discusses knowledge-sharing behavior among lecturers.

There are two main poles of knowledge-sharing behavior among lecturers (and many shades between): knowledge-sharing and knowledge hoarding. When a lecturer demonstrates knowledge-sharing behavior, s/he has the willingness to share knowledge with their colleagues. Lecturers can choose with whom, when, how, and what s/he will do. If a lecturer does not want to share his/her knowledge with others, it is referred to as knowledge-hoarding behavior. This can occur at the same time and place and/or at a different time and place as knowledge-sharing behavior.

Those behaviors are influenced by several factors, among them are intrinsic and extrinsic factors (Davenport \& Prusak, 1998; Bock \& Kim, 2002; Ryu, Ho \& Han, 2003; Bock, Zmud \& Kim, 2005; Lin, 2007; Chatzoglou \& Vraimaki, 2009; Jeon, Kim \& Koh, 2011; Chennamaneni, Teng \& Raja, 2012). These factors are also determined by the relationships among lecturers. Boer, Berends, van Baalen (2011) found that people only share if they are comfortable with each other. In this case, relationships can affect the intrinsic factors of one's behavior. Finally, it will influence one's knowledge-sharing behavior. These factors will be discussed further in the next subsection.

\subsection{Factors Affecting Knowledge-sharing Behavior}

The aforementioned behavioral characteristics explained that behavior is dynamic, observable, measurable, and changeable and so is knowledge-sharing behavior. Knowledge-sharing behavior is not static. It can be seen and recorded, and it can be changed. We must know the factors that affect personal attitude and environment, because the changing of behavior depends on personal attitudes and the environment (Nelson \& Quick, 2012; Miltenberger, 2012), so to predict knowledge-sharing behavior, this study applied the Theory of Reasoned Action (TRA) to explain the factors that influence lecturer's knowledge-sharing intention. Besides applying the TRA, this study uses a relational model theory (RMT) to explain how a relationship can affect the factors that influence knowledge-sharing behavior.

\subsubsection{Theory Reasoned Action (TRA) on Knowledge-sharing Behavior}

The Theory of Reasoned Action (TRA) was developed by Fishbein \& Ajzen in 1980. The TRA had been used in many studies to predict knowledge-sharing behavior (Bock \& Kim, 2002; Ryu, Ho \& Han, 2003; Bock, Zmud \& Kim, 2005; Lin, Lin \& Huang, 2008; Jeon, Kim \& Koh 2011; Chennamaneni, Teng \& Raja, 2012). To perform the behavior, there are one or more considerations to be fulfilled (Fishbein \& Ajzen, 2011). One must have a strong positive intention to perform it.

According to the TRA, people perform or do not perform knowledge-sharing behavior depending on his/her intention for it to happen. The degree of intention (strong or weak) will determine the actual behavior. The intention is determined by a personal 'attitudinal' factor and a social or 'normative' factor (Fishbein \& Ajzen, 2011). The personal 'attitudinal' factor (dubbed 'ATT' for the purposes of this study) is one's reaction toward specific stimuli, whether favorable or unfavorable. The social or 'normative' factors, known as subjective norms, are the influence of the social environment on behavior. As a social influence, the subjective norms are one's thinking about what people expect him/her to do or not to do.

Many researchers have validated the TRA model's ability to predict knowledge-sharing behavior. Ryu, Ho \& Han (2003) found that the TRA was valid in explaining physicians' intention to share knowledge. Subjective norms (SN) were found to have the strongest total effect on physicians' knowledge-sharing intention. Bock, Zmud \& Kim (2005) also found that attitudes and subjective norms affected one's behavioral intention toward knowledge-sharing. On the other hand, Chatzoglou \& Vraimaki (2009) found that an employee's attitude influences intention behavior on knowledge-sharing. This finding shows that even though two determinants of behavior intention are valid, the weight of each determinant can be different in different objects of study. This study applies the TRA model to predict lecturer knowledge-sharing behavior intention and actual knowledge-sharing behavior. 


\subsubsection{Relational Model Theory on Knowledge-sharing Behavior}

Because knowledge-sharing generally involves human interaction, it is affected by relationships. The relational model theory (RMT) had been used to explain this relationship (Boer, van Baalen \& Kumar, 2002; Boer \& Berends, 2003; Boer, Berends \& van Baalen, 2011, Lin, Wu \& Lu, 2012). RMT was developed by Fiske (1992) who assumed humans are fundamentally sociable not individualist. RMT explains social life as a process of seeking, making, sustaining, repairing, adjusting, judging, construing, and sanctioning relationships (Fiske, 1992). In their social life, people are trying to recognize the relationships they want and need. According to Fiske (1992), there are four fundamental relationships that exist in human interaction: communal sharing (CS), authority ranking (AR), equality matching (EM), and market pricing (MP) relationships (Haslam \& Fiske, 1999). People use these four forms of relationship when they organize relationships with others, including in a university.

First, communal sharing represents collective and solid relationships. It requires membership in the group where all of the members are treated equally and there is no special treatment among members. Second, authority ranking refers to a relationship that occurs because of hierarchy. An individual with the highest authority has the highest authorization to command, protect, dominate, and proceed. The lower levels are expected to defer, obey, be loyal and be respectful. Third, equality matching relationships are associated with balanced and imbalanced relationships. People tend to have interaction with others if they expect to get something from the relationship such as reciprocity, equal sharing, democratic voting, and tit-for-tat retaliation. The last form of relationship is market pricing. It refers to a relationship that is based on a tangible reward. "There is no such free lunch" is the foundation of this relationship. In this relationship, there is always a rational calculation of cost and benefit (Haslam \& Fiske, 1999).

Those four fundamental relationships exist in knowledge-sharing behavior. Therefore, people will share based on the relationship they have. They are free to choose with whom they want and need to share their knowledge and their purpose for doing so. In knowledge-sharing activities, the most common form is the communal sharing relationship, which is known as 'community of practice' (COP), where people with common interests build a group of interest. The authority ranking relationship is developed because of resources dependency - such as knowledge, power, et cetera among the members in the group. One who has the resource can put a pressure on others who do not have it. The equality matching relationship in knowledge-sharing is a balanced relationship because people prefer an equal relationship; both the source and recipient of knowledge feel they have an obligation to make a balanced relationship voluntarily. The market pricing relationship in knowledge-sharing behavior exists because people are aware that knowledge is a valuable asset. The scarcity of knowledge builds an intellectual market among those who have it. Because knowledge-sharing is timeconsuming, the longer time one spends on knowledge-sharing, the bigger the opportunity that costs will occur.

Those four forms of relationship occurs when lecturers share their knowledge with others. Since lecturers' relationship is a collegial relationship, this study focuses only on equality matching relationship. In a collegial relationship, the lecturers intend to share their knowledge with others and get knowledge from others equally. Boer, van Baalen and Kumar (2002) said that in academic community, knowledge is commonly shared with colleagues based on the equality matching principles.

There are four principles in equality matching relationships. The first principle is there should be a reciprocal exchange, where people give and get back similar things in return. This is known as a balanced relationship (Blau, 1967). Second, is distributive justice, meaning that everyone gets identical shares. Third, the social influence is compliance to return a favor where everyone keeps things in balance with others. Fourth, the constitution of the groups is equal, which means that everyone has equal status in the groups.

\subsection{The Effect of Equality Matching Relationships on Knowledge-sharing Behavior}

As mentioned above, lecturers' relationships are developed based on the collegial relationships, where the lecturers have the same power or authority. They have the same rights and opportunity to share or not with others. In equality matching relationships, the members are egalitarian. In term of knowledge-sharing, the lecturer will contribute only with those who can return equally. For example, if $A$ shares teaching materials to $B$; then $B$ in the future should share their opinions/resources to enrich A's teaching material. Lecturers will only share with others if they know that they can acquire valuable knowledge (Boer, van Baalen \& Kumar, 2011).

This relationship is a one-on-one relationship. The relationship is developed based on one's expectation of receiving similar knowledge in return in the future (Boer \& Berends, 2003). Lin, Wu and Lu (2012) found that equality matching relationships influence knowledge-sharing behavior positively and efficiently. It means that one will have motivation to share if he/she is in an equality matching relationship. Meanwhile, Ye, Liu, Lin \& Chen (2013) found that 
equality matching relationships have a positive influence on the knowledge-sharing behavior of explicit knowledge but not of tacit knowledge. They explained that people are more hesitant to share their unique and valuable tacit knowledge because in equality matching relationships, the reciprocity is based on moral obligation and there is no guarantee that others will give valuable feedback as expected.

That research examines the direct influence of equality matching relationships on knowledge-sharing behavior. This study argues that equality matching relationships cannot directly influence one's knowledge-sharing behavior. It should be moderated by attitude and environment as the determinants of behavior. So, at first the equality matching relationship influences one's attitude and environment. Then, the attitude and environment influence one's knowledgesharing behavior. This study uses attitude to explain one's positive feeling toward knowledge-sharing and uses subjective norms to explain one's perception of the environmental tendency toward knowledge-sharing.

\section{Methodology}

\subsection{Research Model and Hypotheses}

This study applied the TRA Model and equality matching relationships to predict knowledge-sharing behavior intention among lecturers. Lecturers' knowledge-sharing behavior intention will affect lecturers' actual knowledge-sharing. Based on the explanation in section 2, the research model is constructed as in figure 1.

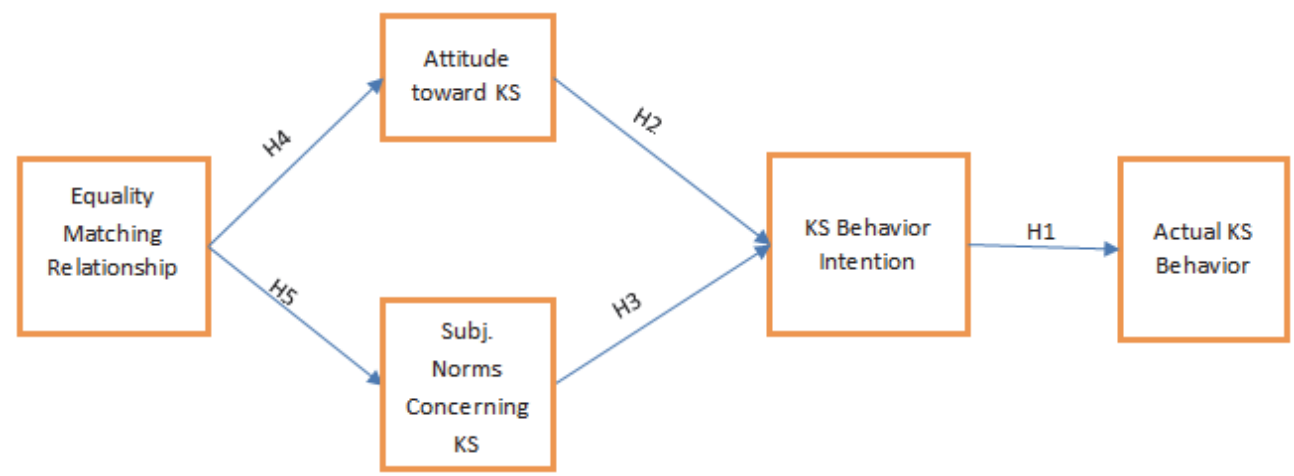

Figure 1. Research Model

The TRA has been used in a wealth of research to predict KS behavior intention (Bock \& Kim, 2002; Ryu, Ho \& Han, 2003; Bock, Zmud \& Kim, 2005; Lin, Lin \& Huang, 2008; Jeon, Koh \& Kim, 2011; Chennamaneni, Teng \& Raja 2012). Many studies have found that attitude and subjective norms have a significant impact on one's intention toward knowledge-sharing. Those studies led to the development of the first three hypotheses as follows:

H1. Lecturers' KS behavior intention affects a lecturers' actual KS behavior positively and significantly.

$\mathrm{H} 2$. Attitude toward KS affects a lecturer's KS behavior intention positively and significantly.

H3. Subjective norms concerning KS affect a lecturer's KS behavior intention positively and significantly.

The lecturer's relationship is usually based on a collegial relationship where everyone has equal status in the group. Lecturers usually share with their colleagues based on equality principles (Bock, van Baalen \& Kumar, 2002) where everyone is expected to have an equal contribution of knowledge to others. The major elements in equality matching relationships are reciprocity, distributive justice, and equality. Many studies confirmed that reciprocity influences one's attitude toward knowledge-sharing behavior positively and significantly (Bock, Zmud \& Kim, 2005, Cabrera, Collins \& Saldago, 2006). People believe their mutual relationships with others can improve their knowledge through knowledgesharing since they have positive attitude toward knowledge-sharing. This empirical evidence leads to the following hypothesis:

H4. Equality matching relationships affect a lecturer's attitude toward KS positively and significantly.

Equality matching relationships affect not only lecturers' attitudes toward KS but also lecturers' subjective norms concerning KS. In equality matching relationships, the awareness of moral obligation to share knowledge equally to others is expected. Therefore, a social influence is needed to create environmental enforcement for individuals to share 
their knowledge, and to make sure that everyone gets equal shares. These theoretical arguments lead to the fifth hypothesis as follows.

H5. Equality matching relationship affects lecturers' subjective norms concerning KS positively and significantly.

\subsection{Research Approach and Data Collection}

This study implemented a quantitative approach. The hypotheses testing and validating were assessed using PLS SEM (partial least square structural equation modeling). Data was collected using a self-administered questionnaire. The questionnaire was developed based on previous literature. The items representing equality matching relationship is modified from Bock, Zmud \& Kim (2002) and Lin, Wu \& Lu (2012). The items of the TRA are adapted from Fishbein \& Ajzen (2011). The items that state actual knowledge-sharing were developed from the interview results with lecturers in Indonesia which consisted of tacit knowledge and explicit knowledge. The items in the questionnaire employed a six-point Likert-type rating scale. This scale measured respondents' level of agreement on the statements (1=strongly disagree; $2=$ disagree; $3=$ somewhat disagree; 4=somewhat agree; 5 =agree and $6=$ strongly agree).

This study was conducted in business and management study programs in Jakarta, Depok, Tangerang, Bogor, and Bekasi (Indonesia). The data were collected in June 2015. From 180 questionnaires that were distributed to permanent lecturers, 154 responses were successfully gathered. The responses were analyzed by using the descriptive analysis feature of SPSS 20 software. The results were confirmed with interviews with 13 lecturers in business and management study programs in Jakarta and Bogor.

\section{Data Analysis and Results}

\subsection{Descriptive Analysis}

\subsubsection{Profile of Respondents}

The respondents of this study are lecturers in 13 business administration and management study programs in Jakarta, Depok, Tangerang, Bogor, and Bekasi (Indonesia). The respondents represent four levels of academic ranks which are lecturer, senior lecturer, associate professor, and professor. The lecturers with academic ranks were the major respondents of this study (53.9\%), followed by senior lecturers $(29.9 \%)$. Meanwhile, the respondents with teaching experience $<10$ years are the majority of the respondents (49.9\%), followed by the respondents with teaching experience $10-20$ years (26.1\%), and over 20 years of teaching experience (24\%).

\subsubsection{Lecturers' Perception toward Knowledge-sharing}

There are five variables in this study: an equality matching relationship; attitude toward knowledge-sharing; subjective norms concerning knowledge-sharing; behavior intention toward knowledge-sharing; and actual knowledge-sharing. The responses to each variable represent the lecturers' perception toward knowledge-sharing as the answer of research question 1.

\subsubsection{Equality Matching Relationships}

As mentioned above, equality matching relationships are relationships based on a balanced exchange among individuals. People will give if they know that they can get the same thing in return. This study measured equality matching relationships with four statements which represent reciprocity and equality. Table 1 shows the respondents' responses regarding this variable. 
Table 1: Descriptive analysis of Equality Matching Relationships

\begin{tabular}{lccccc}
\hline Statements & N & Min & Max & Mean & Std. Devi \\
\hline I expect response from others when I share & 154 & 3 & 6 & 5.01 & 0.75 \\
\hline I believe I can extend my networking when I share & 154 & 3 & 6 & 5.09 & 0.70 \\
\hline When I share it will make my job easier & 154 & 3 & 6 & 5.03 & 0.77 \\
\hline Variable Equality Matching Relationship & 154 & 3 & 6 & 5.04 & 0.74 \\
\hline Valid N (list wise) & 154 & 3 & 6 & 5.04 & \\
\hline
\end{tabular}

Table 1 shows that all statements have almost the same mean. These results show that lecturers expect by sharing knowledge, they can get responses from others, extend the networking and make their job easier. The overall score of equality matching relationships is 5.04 . It means that there is high expectation from the respondents that there will be mutually beneficial relationship in knowledge-sharing activity. This result is confirmed with the interview results, as stated by one of the informants:

"Our knowledge-sharing is based on transactional sharing. I share if we know that others will do the same things as I do."

\subsubsection{Attitude Toward Knowledge-sharing}

Attitude toward knowledge-sharing is one's feeling regarding whether or not to share knowledge with others. Five statements were developed to measure this variable. The respondents' responses are shown in Table 2.

Table 2: Descriptive Analysis of Attitude Toward Knowledge-sharing

\begin{tabular}{lccccc}
\hline Statements & N & Min & Max & Mean & Std. Devi \\
\hline To me, knowledge-sharing is a good thing & 154 & 2 & 6 & 5.64 & 0.49 \\
\hline To me, knowledge-sharing is harmless & 154 & 2 & 6 & 5.28 & 0.58 \\
\hline To me, knowledge-sharing is fun & 154 & 2 & 6 & 5.29 & 0.63 \\
\hline To me, knowledge-sharing is valuable & 154 & 2 & 6 & 5.37 & 0.55 \\
\hline To me, knowledge-sharing gives is beneficial & 154 & 2 & 6 & 5.50 & 054 \\
\hline Variable Attitude Toward Knowledge-sharing & 154 & 2 & 6 & 5.41 & .56 \\
\hline Valid N (list wise) & 154 & & & & \\
\hline
\end{tabular}

Table 2 indicates the lecturers' have positive feelings toward knowledge-sharing which can be seen from the mean score of the variable (5.41). The positive response also can be seen from the item's mean score. For example, the statement about knowledge-sharing is a good thing has a mean score of 5.64 (out of 6 ). The lowest score level in this variable is a statement about knowledge-sharing being harmless (5.28) which indicated that respondents agree that knowledgesharing is not a threat for them. This result is confirmed with the interview results, as stated by one of the informants:

"I share because I think it's very important for lecturers to share to others. It is not harmful, on the contrary, if we share others will know what we do."

\subsubsection{Subjective Norms Concerning Knowledge-sharing}

The subjective norms variable consists of four statements. Those statements expressed how the environment (superordinate and colleagues) expects one to share his/her knowledge to others. Table 3 shows the respondents' responses to those statements. 
Table 3: Descriptive Analysis of Subjective Norms Concerning Knowledge-sharing

\begin{tabular}{lccccc}
\hline Statements & $\mathbf{N}$ & Min & Max & Mean & Std. Devi \\
\hline Head of department/study program encourages me to share knowledge & 154 & 1 & 4 & 4.30 & 1.32 \\
\hline Coordinator of interest group encourages me to share knowledge & 154 & 1 & 5 & 4.44 & 1,09 \\
\hline My colleagues encourage me to share knowledge & 154 & 1 & 5 & 4.66 & 0.91 \\
\hline lobey the rules & 154 & 1 & 4 & 4.74 & 0.91 \\
\hline Variable Subjective Norms Concerning Knowledge-sharing & 154 & 1 & 5 & 4.54 & 1.06 \\
\hline Valid N (list wise) & 154 & & & \\
\hline
\end{tabular}

The results in table 3 indicate that respondents had almost the same level of agreement on those statements. The statement about "my colleagues encourage me to share knowledge" has the highest mean score (4.74). This means the social motivation to share knowledge is mostly from the colleagues. The lowest mean score is a statement about "the head of department/study program encourages me to share knowledge" (4.44). The overall mean score of variable subjective norms concerning knowledge-sharing behavior is 4.54 which means that the social pressure for lecturers to share to others is not strong enough. In other words, the environment does not have social enforcement for lecturers to share their knowledge with others. From the interview result, it is found that only 2 universities had subjective norms concerning knowledge-sharing. Those norms are set by the leader, the Dean or the head of department, as stated by one of the informants as follows:

"The dean motivates us to share our knowledge. He conducts a regular monthly meeting. In the meeting, we can share and ask for as much knowledge as we want."

\subsubsection{Lecturer's Knowledge-sharing Behavior Intention}

As the beginning process of lecturers' actual knowledge-sharing behavior, the behavior intention plays an important role because without the intention, the behavior will not be performed. The variable of lecturers' knowledge-sharing behavior consisted of seven statements. The respondents' responses are shown in Table 4.

Table 4: Descriptive analysis of Lecturer's Knowledge-sharing Behavior Intention.

\begin{tabular}{lccccc}
\hline Statements & N & Min & Max & Mean & Std. Devi \\
\hline I will share my teaching materials & 154 & 4 & 6 & 5.18 & 0.57 \\
\hline I will share my research report & 154 & 2 & 6 & 4.99 & 0.69 \\
\hline I will share my teaching and research database & 154 & 1 & 6 & 4.87 & 0.84 \\
\hline I will share things relating to the organization (policy, procedures) & 154 & 2 & 6 & 4.98 & 0.75 \\
\hline I will share how to teach & 154 & 2 & 6 & 4.92 & 0.77 \\
\hline I will share how to get research funding/grants & 154 & 2 & 6 & 4.94 & 0.73 \\
\hline I will share my skills from education and training & 154 & 2 & 6 & 4.99 & 0.70 \\
\hline Variable Lecturer's Knowledge-sharing Behavior Intention & 154 & 1 & 6 & 4.98 & 0.72 \\
\hline Valid N (list wise) & 154 & & &
\end{tabular}

Table 4 shows that the every lecturer has the intention to share his/her knowledge with others. The majority of respondents agreed to sharing their teaching material. Sharing teaching materials is commonly used to set the standard in teaching, so that every lecturer delivers the same teaching materials to the students. The lowest score in the intention to share variable is sharing teaching and research database (4.87). Even though it is the lowest score, it does not mean that lecturers hoard the knowledge. They will share if others ask them to, this evidence is found from the interview results regarding knowledge-sharing intention, as stated by one of the informants:

"I will share if others ask me to share. Because I do not know what he/she needs. If I share just like that, I'm afraid that others will see me as a show-off. I will share everything, but they have to ask me first."

\subsubsection{Lecturer's actual knowledge-sharing}

The respondents were given seven statements which represent their actual knowledge-sharing behavior. Those statements are derived from the intention items. Table 5 shows the respondents' responses to those items. 
Table 5: Descriptive Analysis of Lecturer's Actual Knowledge-sharing Behavior

\begin{tabular}{lccccc}
\hline Statements & N & Min & Max & Mean & Std. Devi \\
\hline I will share my teaching materials & 154 & 4 & 6 & 5.09 & 0.71 \\
\hline I will share my research report & 154 & 2 & 6 & 4.81 & 0.86 \\
\hline I will share my teaching and research database & 154 & 1 & 6 & 4.75 & 0.93 \\
\hline I will share things relating to the organization (policy, procedures) & 154 & 2 & 6 & 4.81 & 0.85 \\
\hline I will share how to teach & 154 & 2 & 6 & 4.79 & 0.90 \\
\hline I will share how to get research funding/grants & 154 & 2 & 6 & 4.85 & 0.78 \\
\hline I will share my skills from education and training & 154 & 2 & 6 & 4.84 & 0.85 \\
\hline Variable Lecturer's Knowledge-sharing Behavior Intention & 154 & 1 & 6 & 4.84 & 0.84 \\
\hline Valid N (list wise) & 154 & & & & \\
\hline
\end{tabular}

The results of lecturers' actual knowledge-sharing behavior are almost the same with the result of the lecturers' intention to share. Table 5 shows that the highest mean score is sharing teaching material (5.09). The explanation of this result is that in Indonesia, teaching is the focus of lecturers' duty above all duties (research and community service), and there are some classes with the same subject but different lecturers which require the same treatment. So every lecturer should deliver the same teaching materials to the students. Sharing the teaching materials to others can be used to maintain teaching standards. The overall score of the lecturers' actual knowledge-sharing is 4.84 which indicates that the actual knowledge-sharing is not intensive enough.

\subsection{Effects of Equality Matching Relationship on Knowledge-sharing Behavior Among Lecturers}

To answer research question no.2, this study applied PLS SEM (partial least square structural equation modeling). The PLS SEM was used as it allows latent constructs to model either formative or reflective indicators. PLS SEM requires a minimal sample size to validate a model (Chin, 1998). The data processing was using SmartPls 3.0. PLS data processing required a valid measurement from the statement items and variables. The study assessed three types of validity measurement: content, convergent, and discriminant validity. Content validity was established by ensuring consistency between measurement items and the previous literature. This was conducted by interviewing some lecturers and pilottesting the instrument. The convergent validity was assessed by examining composite reliability (CR) and average variance extracted (AVE) (Hair, Anderson, Tatham \& Black, 1998). The CR values range from 0.809 to 0.941 , which indicate that the construct was reliable (above the threshold value 0.7). Meanwhile, the AVE scores range from 0.586 to 0.815 , which are above the acceptability value (0.5). The discriminant validity was verified by looking at the square root of the AVE. The square root of the AVE for each construct is greater than the levels of correlations involved in the construct. From those measurements of validity and reliability, the model which is constructed in this study is valid and reliable.

This study applies SmartPLS 3.0 to examine the relationships among the variables; the result is shown in figure 2. The equality matching relationship influences attitude and subjective norms positively, where the influence is higher on the attitude toward knowledge-sharing than on subjective norms.

Figure 2 also shows that all hypotheses are significant at the 99 and $99.9 \%$ level of confidence, except hypothesis H5. Besides that, figure 2 shows that knowledge-sharing behavior intention influence actual knowledge-sharing behavior. The implication is that to perform knowledge-sharing behavior, the lecturers should have a positive feeling driven by the equality matching relationship. 


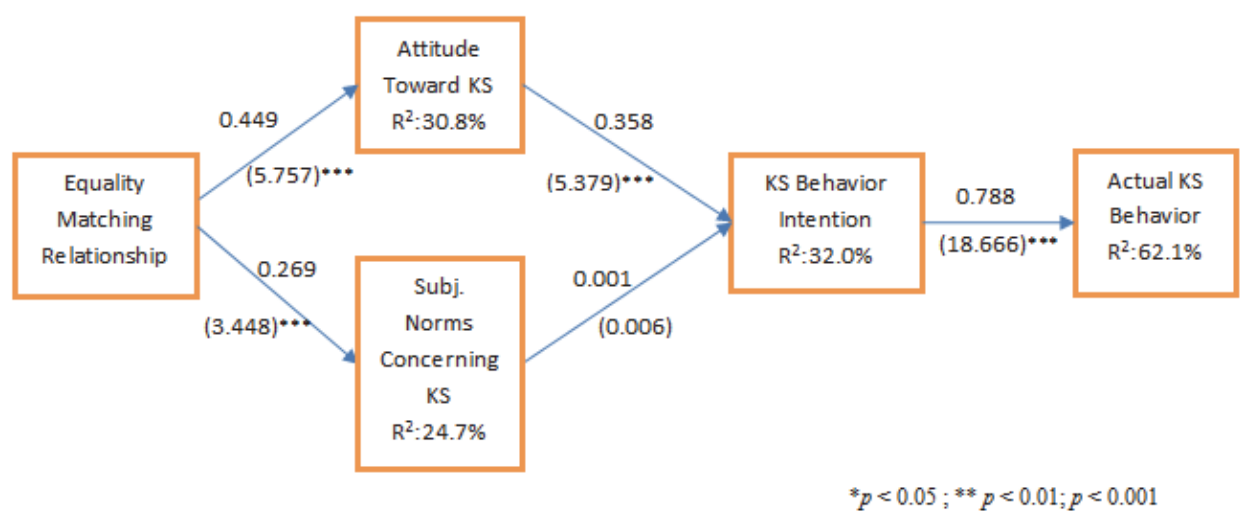

Fig 2. Hypotheses testing of research model

\section{Discussions and Limitations of Study}

Figure 2 shows that EM relationship had an impact on lecturers' behavior intention and finally will influence lecturers' knowledge-sharing behavior. The findings are in line with Boer, van Baalen \& Kumar (2002), Lin, Wu \& Lu (2012), Ye Liu, Lin \& Chen (2013). They found that equality matching relationships influence one's behavior intention positively and significantly.

Based on the findings, equality matching relationships can be used to explain one's intention to share his/her knowledge with others. Since the lecturers have the awareness that knowledge is a valuable asset that they have, when they share it, they expect others to share similar valuable knowledge with them. The feeling of equality motivates the lecturers to share their knowledge to others. To be able to have an equality matching relationship, there are some considerations that a university should fulfill:

1. Elevate lecturer competencies: To be able to share, one must have certain level of competencies or unique knowledge. The competency level between knowledge sharers and receivers should be at the same level because by having the same competency level, the knowledge exchange can be performed. Therefore, every lecturer should endeavour to elevate his/her competencies so that he/she can engage in knowledge-sharing activities.

2. Leadership commitment on creating knowledge-sharing culture: The commitment of the leader, or at least the leader at departmental level or faculty level, to create knowledge-sharing atmosphere is very important. The leader can spent more on buying material resources and share them with the lecturers. Besides using the structural approach, the leader should use his/her personal approach to know individual lecturers' expectations. By knowing their expectations, it will be easier for the leader to encourage the lecturers to share their knowledge.

As mentioned in the introduction section, there are two contributions to this study. This study provides additional evidence that attitude and subjective norms are influenced by the relationships, in this case equality matching relationships. Second, this study does not only examine the knowledge-sharing behavior intention but also examine the actual knowledge-sharing behavior which is influenced by TRA and equality matching relationships.

However, besides its contributions, this study has some limitations. First, this study only uses one of the social relationships to explain lecturers' knowledge-sharing behavior. Second, due to time, space, and resource limitations, the data collection is limited to business and management study programs in Jakarta, Bogor, Tangerang, and Bekasi (Indonesia), so the findings cannot be generalized to all study programs. These limitations leave successors room for continuing the study on the effect of other social relationships on knowledge-sharing behavior.

\section{References}

Ajzen, I., \& Fishbein, M. (2011). Predicting and Changing Behavior: The Reasoned Action Approach. New York: Taylor \& Francis Group. Alajmi, B. (2008). Understanding Knowledge-Sharing Behavior: A Theoretical Framework. Knowledge Management in Organizations. 
Alavi, M., \& Leidner, D. (2001). Review: Knowledge management and knowledge management systems: Conceptual foundations and reseach issues. MIS Quaterly, 25(1), 107-136.

Blau, P. (1967). Exchange and Power in Social Life. New York: JohnWiley \& Sons.

Bock, G., \& Kim, Y. (2002). Determinants of the individual's knowledg sharing behavior: The theory of reasoned action perspective. The Pacific Asia conference on information system.

Bock, G., Zmud, R., \& Kim, Y. (2005). Behavior intention formation in knowledge sharing: Examining the roles of extrinsic motivators, social-psychological forces, and organizational climate. MIS Quaterly, 29(1), 89-111.

Boer, N., \& Berends, H. (2003). The relational dimension of knowledge sharing: An empirical study of an industrial research group. Fourth European Conference on Organizational Knowledge (OKLC). Barcelona.

Boer, N., Berends, H., \& van Baalen, P. (2011). Relational Models for Knowledge Sharing Behavior. European Management Journal, 29 (2), 85-97.

Boer, N., van Baalen, P., \& Kumar, K. (2002). The implications of different model of social relationship for understanding knowledge sharing. The Third European Conference on Organizational Knowledge, Learning and Capabilities (OKLC). Athens, Greece.

Cabrera, Collins, W., \& Salgado, J. (2006). Determinants of individual engagement in knowledge sharing. International Journal of Human Resource Management, 17(2), 245-264.

Chatzoglou, P., \& Vraimaki, E. (2009). Knowledge-sharing behavior of bank employes in Greece. Business Process Management Journal, 15 (2), 245-266.

Chennamaneni, A., Teng, J., \& Raja, M. (2012). A unified model of knowledge sharing behaviours: Theoretical Development and Empirical Test. Behavior \& Information Technology, 31(1), 1097-1115.

Chin, W. (1998). The Partial Least Squares Approach to Structural Equation Modeling. In G. Marcoulides, Modern Methods for Business Research (pp. 295-336). Mahwah, NJ: Laurence Erlbaum Associates.

Chong, C., \& Besharati, J. (2014). Challenging in knowledge sharing in petrochemical industry. Knowledge Management \& E-Learning, 6(2), 171-187.

Connely, C., \& Kelloway, E. (Leadership and Organizaton Development Journal, 24 (5)). 2003. Predictors of employees' perceptions of knowledge sharing cultures, 294 - 301.

Davenport, T., \& Prusak, L. (1998). Working Knowledge: How organization manage what they know. Boston, Mass: Harvard Business School.

Drucker, P. (1994). Theory of The Business. Boston: Harvard Business Review.

Fiske, A. (1992). The four elementary forms of sociality: framework of a unified theory of social relations. New York: Free Press.

Gupta, A., \& Givindarajan, V. (2000). Knowledge flows within multinational corporations. Strategic Management, 21, 473-496.

Hair, J., Anderson, R., Tatham, R., \& Black, W. (1998). Multivariate Data Analysis (5th ed.). Englewood Cliffs, NJ: Prentice Hall.

Haslam, N., \& Fiske, A. (1999). Relational models theory: A confirmatory factor analysis. Personal Relationships, 6, 241-250.

Jeon, S., Kim, Y., \& Koh, J. (2011). An Integratice Model of Knowledge Sharing in Communities of Practice. Journal of Knowledge Management, 15 (2), 251-269.

Jewels, T., \& Ford, M. (2006). Factors influencing knowledge sharing in information technology projects. e-Service Journal, 5(1), $99-117$.

Lin, F.-R., Lin, S.-C., \& Huang, T. (2008). Knowledge shairng and creation on a teacher's professional virtual community. Computer \& Education, 50, 742-756.

Lin, H. (2007). Effects of extrinsic and intrinsic motivation on employee knowledge sharing intentions. Journal of Information Science, 33, 135-149.

Lin, J., \& Wang, C. (2005). An examination on relationships among competence, social capital, and organzatioal citizen sharing behaviors. Asia-PAcific Economis and Management Review.

Lin, T.-C., Wu, S., \& Lu, C.-T. (2012). Exploring the affect factors of knowledge sharing behavior: The relations model theory perspective. Expert Systems with Applications, 751-764.

Miltenberger, R. (2012). Behavior Modification: Principles and Procedures. CA: Wadsworth Cengage Learning.

Nelson, D., \& Quick, J. (2012). Organizational Behavior: Science, The Real World, and You. Mason, Ohio: South-Western, Cengage Learning.

Nelson, K., \& Cooprider, J. (1996). The Contribution of Shared Knowledge to IS Group Performancel. MIS Quarterly, $20,409-429$.

Polanyi, M. (1962). Personal Knowledge. London: Routledge and Kegan Paul.

Riege, A. (2005). Three-dozen knowledge-saring barriers managers must consider. Journal of Knowledge Management, 9 (3), 18-35.

Ryu, S., Ho, S., \& Han, I. (2003). Knowledge sharing behavior of physisians in hospital. Expert Systems with Applications, 25(1), 113122.

Sekaran, U., \& Bougie, R. (2009). Research Methods for Business: A Skill Building Approach. New York: JohnWiley \& Sons.

Shapira, P., Youtie, J., \& Jaafar, Z. (2005). Knowledge Economy Measurement: Methods, Results and Insights from Malaysian Knowledge Content Study. Triple Helix 5 Conference on New Indicators for the Knowledge Economy. Turin, Italy.

Sharatt, M., \& Usoro, A. (2003). Understanding Knowledge-Sharing in Online Communites of Practice. Electronic Journal on Knowledge Management, 1(2), 187-196.

Skyrme, D. (1999). Knowledge Management: Building the Collaborative Entreprise. London: Ovum.

Wang, S., \& Noe, R. (2010). Knowledge sharing: A Review and directions for future research. Human Resource Management Review, 20 (2), 115-131.

Wasko, M., \& Faraj, S. (2005). Why should I share? Examining social capital and kwowledge contribution in electronic networks of 
practice. MIS QUaterly, 29(1), 35-57.

Ye, D., Liu, Z., Lin, T.-C., \& Chen, C.-M. (2013). A Study of Knowledge sharing Among Different Models: Communal Sharing, Authority Ranking, Equality Matching and Market Pricing. 24th Annual Conference of the Production and Operations Management Society (pp. 1-10). Colorado, USA: Michigan State University. 